\title{
Genetic Variability and Correlation Studies in Chickpea under Timely and Late Sown Environments
}

\author{
A.G. Vijayakumar ${ }^{1 *}$, H.L. Nadaf ${ }^{2}$, V.B. Nargund ${ }^{3}$ and B.C. Patil ${ }^{4}$ \\ ${ }^{1}$ Department of Genetics and Plant Breeding, College of Agriculture, UAS, Dharwad, India \\ ${ }^{2}$ Director of Research, UAS, Dharwad, India \\ ${ }^{3}$ Department of Plant Pathology, CoA, Dharwad, India \\ ${ }^{4}$ Department of Crop Physiology, CoA, Dharwad, India
}

*Corresponding author

\section{A B S T R A C T}

Chickpea is a cool season pulse and suffers severe yield losses when exposed to higher temperatures during reproductive phase. Stable chickpea production will depend on the release of new cultivars with improved adaptation to drought and high temperature. Twenty five breeding lines of two crosses JG 11 x JG 14 and JAKI 9218 x JG 14 were assessed under timely and late sown situations.

\section{Ke y w o r ds}

Chickpea (Cicer arietinum $\mathrm{L}$.), Genotypes, South America

\section{Article Info}

Accepted:

20 June 2019

Available Online:

10 July 2019 High variability was observed for majority of the traits in both the seasons. In late sown condition high GCV and PCV was recorded for days to fifty per cent podding, number of pods, yield per plant, hundred seed weight, pollen viability and per cent membrane leakage at 50 days. Ample variability available for these traits can be exploited by direct selection. In general the late sown crop matured early due to restricted reproductive period and hastened maturity. Higher heritability for days to first and fifty per cent podding, days to maturity, pollen viability and hundred seed weight was noticed under late sown environments. Higher estimates of GCV (\%), heritability and genetic advance as per cent of mean were noticed for plant height $(\mathrm{cm})$, first pod height $(\mathrm{cm})$, number of pods per plant, yield per plant (g/plant) and hundred seed weight $(\mathrm{g})$. Occurrence of high estimates of heritability coupled with genetic advance as per cent of mean for these traits suggest that these traits can be considered as favourable attributes for improvement through selection. Number of pods per plant was positively and significantly associated with number of branches per plant $(0.470)$, plant height (0.509) and first pod height (0.493) signifying that early maturing genotypes with better canopy spread are capable of escaping heat stress under late sown environment. Hundred seed weight (g) was positively and significantly associated with number of pods per plant $(0.480)$ and days to maturity (0.666). Important attributes under late sown environment were plant height, number of pods per plant, hundred seed weight and per cent membrane leakage at 50 days.

\section{Introduction}

Chickpea (Cicer arietinum L.) is widely cultivated around the world covering more than 50 countries spread over Asia, Africa, Europe, Australia, North and South America. In India it is cultivated across all parts of the country. Chickpea area and production in
India during 2017-18 was $10.56 \mathrm{mha}$ and $11.23 \mathrm{mt}$, respectively. The Central and Southern states viz., Maharashtra, Madhya Pradesh, Rajashtan, Gujarath, Andhra Pradesh, Chattisgarh and Karnataka account for major share in area and production and have largely benefitted from chickpea revolution in the country. Over the last few decades, traditional 
chickpea cultivation from Northern India, where low temperature and prolonged winter favour the crop has been replaced by warmer areas of Central and Southern India. This shift of chickpea cultivation to warmer and relatively harsher growing environments have allowed focused research on development of early maturing varieties, capable of escaping terminal drought and heat stress and resistance to biotic stresses viz., Fusarium wilt and off late dry root rot (Dixit et al., 2019). Heat stress coupled with terminal drought is a major constraint in chickpea under warmer short season environments. A drastic reduction in yield of chickpea occurs when the crop is exposed to day temperatures of $35^{\circ} \mathrm{C}$ and above during reproductive phase (Devasirvatham, 2012). High temperature is known to induce damaging effects on seed germination, photosynthesis, reproductive development, seed set and seed quality (Devasirvatham et al., 2015). Selection for yield on basis of per se performance alone may not be effective as compared to selection based on the component characters associated with it, which is biometrically estimated with correlation coefficient. Hence, variability and correlation studies under different environments provide practical insight regarding pattern of changing variability under diverse situations and assessing the consequences of selecting one or more traits. Hence, present study was undertaken to assess variability and association among yield contributing traits among the selected chickpea genotypes grown in two different seasons.

\section{Materials and Methods}

JG 11 and JAKI 9218 are popular varieties of North Karnataka, however, their cultivation is restricted to sowing under normal season (September 25th - October 30th sowing), beyond which, the yield losses are high due high temperature stress. Availability of irrigation water in command areas also necessitates the need to identify suitable breeding lines for late sown cultivation. JG 14 is a heat tolerant variety released from JNKVV, Jabalpur for cultivation under heat stress environments. However, the acceptance of variety in North Karnataka region is limited due to seed characters. The experiment material comprised of twenty five progenies derived from two crosses viz., JG 11 x JG 14 and JAKI 9218 x JG 14 evaluated with five checks. The $\mathrm{F}_{3}$ breeding lines were screened under normal environment during rabi 2017 for yield and related parameters as well as resistance to Fusarium wilt. The wilt resistant and high yielding $\mathrm{F}_{4}$ lines of these crosses were evaluated under heat stress environment during summer 2018. The field experiments were conducted under randomized complete block design with two replications at Plant Breeding block of AICRP for Dry land Agriculture, RARS, Vijayapur during rabi 2017 and summer 2018. The Regional Agricultural Research Station, Vijayapur is situated at $16^{\circ} 49^{\prime} \mathrm{N}$ latitude and $75^{\circ} 45^{\prime} \mathrm{E}$ longitude at 593 meters above mean sea level. It is classified under Northern Dry Zone (Zone 3 ) of Karnataka and is characterized by deep to medium deep block soils with $\mathrm{pH}$ of 7.8 to 8.2 and an annual average rainfall of $596 \mathrm{~mm}$. Each entry was sown in single row of 3 meters with a spacing of 30 centimeters between rows and 10 centimeters between plants. The normal season crop was sown on $7^{\text {th }}$ October 2017, while the late season crop was planted on $2^{\text {nd }}$ February 2018 to expose the summer crop for high temperature stress. All recommended practices were followed to raise a good crop during both the seasons. Five plants per replication and per genotype were randomly selected for recording the observations on 15 growth and yield related traits

In order to assess the genetic variability among the genotypes for the characters under 
study, the genetic parameters such as genotypic coefficient of variability (GCV\%), phenotypic coefficient of variability (PCV\%), heritability $\left(\mathrm{h}_{\mathrm{bs}}^{2}\right)$, genetic advance (GA) and Genetic advance as per cent of mean (GAM) were estimated. Heritability in the broad sense was derived based on the formula given by Hansan et al., (1956). GA was obtained by the formula prescribed by Johnson et al., (1955). The method adopted by Burton and De Vane (1953) was used to calculate phenotypic and genotypic coefficient of variation. Phenotypic and genotypic correlations among 11 characters were computed as per the formula given by Weber and Moorthy (1950).

\section{Results and Discussion}

In the present investigation an effort was made to assess the variability of $\mathrm{F}_{3}$ and $\mathrm{F}_{4}$ progenies evaluated under normal and late sown conditions, respectively. The analysis of variance for fifteen quantitative traits of 25 progenies derived from two crosses that were assessed under normal and late sown conditions is presented in Table 1. The mean sum of squares due to various sources of variation for quantitative characters indicated that all the characters assessed under two environments showed significant differences, indicating that the variability among the selected progenies was significant. The presence of high variability in the material indicates that through appropriate amelioration of variability of yield contributing traits it would be possible to harness the benefits of higher yield under diverse environments.

The estimates of genetic variability parameters for different quantitative traits are presented in Table 2. The mean values and range of estimates for 15 quantitative characters studied indicated that values for all the characters were higher in the normal season as compared to the late sown situation. The characters days to first flowering, days to fifty per cent flowering, days to first podding, days to fifty per cent podding and days to maturity recorded lesser number of days under late sowing. These differences in the mean values of the reproductive characters may be attributed to restricted reproductive period and hastened maturity due to higher temperatures coinciding during reproductive phase of the late sown crop. Heat stress accompanying the flowering period decreases the duration of developmental phases due to higher diurnal temperatures (Upadhyaya et al., 2011, Devasirvatham et al., 2015). Chickpea being a cool season crop requires diurnal temperature of $15 / 25^{\circ} \mathrm{C}$, night and day temperature for induction of normal flowering and pod setting.

The results related to yield attributes revealed significantly lower values for number of pods per plant (70.53 under normal sowing and 40.60 under late sowing), hundred seed weight (27.24 under normal situation and 22.67 under late sown condition) and yield per plant (18.21 g/ plant under normal sowing and 14.43 g/plant under late sowing) under delayed planting. Yield decline was observed in almost all genotypes due to heat stress.

Yield per plant under heat stress ranged from $9.78 \mathrm{~g} / \mathrm{plant}$ to $27.60 \mathrm{~g} / \mathrm{plant}$ as compared to $13.35 \mathrm{~g} /$ plant to $29.60 \mathrm{~g} /$ plant under timely sowing condition, indicating a decrement of 10-15 per cent yield per plant. Heat stress is known to adversely affect pollen viability, fertilization and seed development leading to reduced harvest index (Gaur et al., 2018). Poor pod set in chickpea can occur due to the failure of male or female floral parts, or both. High temperatures at flowering can affect anther dehiscence. Devasirvatham et al., (2013) concluded that the critical temperature affecting pod set was $\geq 37^{\circ} \mathrm{C}$ for heat-tolerant genotypes (such as ICCV 92944, ICC 1205 and ICC 15614) and $>33^{\circ} \mathrm{C}$ for heat-sensitive genotypes (ICC 5912, ICC 4567 and ICC 10685). 
Table.1 Mean sum of squares for 15 quantitative traits in $\mathrm{F}_{3}$ and $\mathrm{F}_{4}$ progenies of chickpea

\begin{tabular}{|c|c|c|c|c|c|c|c|c|c|c|c|c|c|c|c|c|}
\hline Sources & df & DFF & D50F & DFP & D50P & NBP & PHT & FPH & NPP & DMT & YPP & HSW & PVP & PML50 & TCC50 & Wilt \% \\
\hline \multicolumn{17}{|c|}{ Normal season: Rabi $2017-F_{3}$ progenies } \\
\hline Replication & 1 & $4.32 *$ & $4.93 *$ & $5.95 *$ & $8.43 *$ & 0.07 & 0.01 & 1.73 & 2.01 & 11.79 & 0.880 & 2.64 & 1.83 & 7.42 & 0.028 & 0.231 \\
\hline Genotypes & 29 & $4.77 * *$ & $3.91 * *$ & $10.84 * *$ & $23.85^{* *}$ & $0.39^{* *}$ & $48.69 * *$ & $15.22 * *$ & $181.54 * *$ & $7.64^{*}$ & $26.89^{* *}$ & $33.26^{* *}$ & $167.15^{* *}$ & $118.20^{* *}$ & $0.146^{* *}$ & $317.80^{* *}$ \\
\hline Error & 29 & 0.70 & 0.79 & 1.07 & 1.45 & 0.15 & 7.68 & 4.31 & 26.81 & 3.79 & 1.89 & 2.05 & 20.31 & 8.85 & 0.019 & 2.59 \\
\hline Sem & - & 0.58 & 0.62 & 0.72 & 0.84 & 0.26 & 1.92 & 1.44 & 3.56 & 1.35 & 0.96 & 0.99 & 3.13 & 2.06 & 0.09 & 1.12 \\
\hline CD (0.05) & - & 1.29 & 1.37 & 1.53 & 1.76 & 0.64 & 3.98 & 2.98 & 7.31 & 2.87 & 2.15 & 2.06 & 6.71 & 4.33 & 0.21 & 2.34 \\
\hline \multicolumn{17}{|c|}{ Late season: Summer 2018- $F_{4}$ progenies } \\
\hline Replication & 1 & 0.98 & $2.83^{*}$ & 1.62 & $3.32 *$ & 0.09 & 3.10 & 0.20 & $34.3^{*}$ & $8.91^{*}$ & 10.93 & 1.74 & 0.013 & 10.72 & 0.006 & 0.16 \\
\hline Genotypes & 29 & $2.63 * *$ & $4.16 * *$ & $5.41 * *$ & $6.99 * *$ & $0.265^{* *}$ & $22.85 * *$ & $4.56 * *$ & $63.80^{* *}$ & $3.65^{* *}$ & $22.76^{* *}$ & $7.96 * *$ & $72.89 * *$ & $109.92 * *$ & $0.084 * *$ & $14.41^{* *}$ \\
\hline Error & 29 & 0.35 & 0.65 & 0.93 & 1.10 & 0.02 & 3.12 & 0.69 & 6.70 & 3.84 & 1.29 & 1.83 & 12.07 & 5.85 & 0.04 & 0.69 \\
\hline Sem & - & 0.41 & 0.56 & 0.67 & 0.73 & 0.10 & 1.23 & 0.58 & 1.80 & 1.36 & 0.79 & 0.94 & 2.41 & 1.68 & 0.03 & 0.58 \\
\hline CD (0.05) & - & 1.21 & 1.64 & 1.97 & 2.15 & 0.27 & 2.51 & 1.23 & 3.67 & 2.79 & 1.62 & 1.94 & 4.95 & 3.43 & 0.09 & 1.39 \\
\hline
\end{tabular}

$*, * *$ and $* * *$ indicates significance at $5 \%, 1 \%$ and $0.1 \%$ respectively.

DFF: Days to first flowering, D50F: Days to 50 per cent flowering, DFP: Days to first podding, D50P: Days to 50 per cent podding, NPB: Number of primary branches, PHT: Plant height $(\mathrm{cm})$, FPH: First pod height $(\mathrm{cm})$, NPP: Number of pods per plant, DMT: Days to maturity, YPP: Yield per plant (g), HSW: Hundred seed weight (g), PVP: Pollen viability (\%), PML50: Per cent membrane leakage at 50 days, TCC50 - Total chlorophyll content at 50days, Wilt (\%): Wilting per cent

Table.2 Estimates of genetic variability parameters for different quantitative traits $\mathrm{F}_{3}$ (Normal season rabi 2017) and $\mathrm{F}_{4}($ Late season summer 2018) progenies of different crosses in chickpea

\begin{tabular}{|c|c|c|c|c|c|c|c|c|c|c|c|c|c|c|}
\hline \multirow[t]{2}{*}{ Traits } & \multicolumn{2}{|c|}{ Mean } & \multicolumn{2}{|c|}{ Range } & \multicolumn{2}{|c|}{ GCV (\%) } & \multicolumn{2}{|c|}{ PCV (\%) } & \multicolumn{2}{|c|}{$\mathbf{h}_{(\mathrm{bs})}^{2}(\%)$} & \multicolumn{2}{|c|}{ GA } & \multicolumn{2}{|c|}{ GAM (\%) } \\
\hline & $\begin{array}{c}\text { Rabi } 2017 \\
\left(\mathbf{F}_{3}\right)\end{array}$ & $\begin{array}{l}\text { Summer } \\
2018\left(F_{4}\right)\end{array}$ & Rabi $2017\left(F_{3}\right)$ & Summer $2018\left(\mathbf{F}_{4}\right)$ & $\begin{array}{c}\text { Rabi } 2017 \\
\left(\mathbf{F}_{3}\right)\end{array}$ & $\begin{array}{l}\text { Summer } \\
2018\left(F_{4}\right)\end{array}$ & $\begin{array}{c}\text { Rabi } 2017 \\
\left(F_{3}\right)\end{array}$ & $\begin{array}{l}\text { Summer } \\
2018\left(F_{4}\right)\end{array}$ & $\begin{array}{c}\text { Rabi } 2017 \\
\left(\mathbf{F}_{3}\right)\end{array}$ & $\begin{array}{l}\text { Summer } \\
2018\left(F_{4}\right)\end{array}$ & $\begin{array}{c}\text { Rabi } 2017 \\
\left(\mathbf{F}_{3}\right)\end{array}$ & $\begin{array}{l}\text { Summer } \\
2018\left(F_{4}\right)\end{array}$ & $\begin{array}{c}\text { Rabi } 2017 \\
\left(F_{3}\right)\end{array}$ & $\begin{array}{l}\text { Summer } \\
2018\left(F_{4}\right)\end{array}$ \\
\hline DFF & 41.82 & 39.82 & $37.10-43.15$ & $37.6-41.90$ & 2.68 & 3.59 & 3.07 & 4.16 & 76.00 & 74.00 & 1.92 & 2.53 & 4.83 & 6.37 \\
\hline D50F & 44.60 & 44.22 & $42.05-47.80$ & $41.80-46.70$ & 3.00 & 2.80 & 3.51 & 3.44 & 73.00 & 66.00 & 2.34 & 2.09 & 5.28 & 4.69 \\
\hline DFP & 52.66 & 50.13 & $49.10-57.70$ & $48.50-53.10$ & 2.92 & 4.19 & 3.48 & 4.63 & 71.00 & 82.00 & 2.59 & 4.12 & 5.06 & 7.82 \\
\hline D50P & 61.55 & 58.30 & $56.90-68.70$ & $55.80-62.50$ & 2.90 & 5.43 & 3.40 & 5.77 & 73.00 & 88.00 & 3.01 & 6.48 & 5.10 & 10.53 \\
\hline NBP & 3.22 & 2.69 & $2.25-4.00$ & $2.10-3.70$ & 12.94 & 10.85 & 14.04 & 16.06 & 85.00 & 46.00 & 0.66 & 0.48 & 24.59 & 15.11 \\
\hline PHT & 51.33 & 39.10 & $43.25-59.40$ & $31.40-46.70$ & 8.04 & 8.82 & 9.23 & 10.34 & 76.00 & 72.00 & 5.64 & 7.95 & 14.46 & 15.49 \\
\hline FPH & 22.93 & 16.53 & $18.90-28.40$ & $12.90-20.30$ & 8.43 & 10.18 & 9.81 & 13.62 & 74.00 & 55.00 & 2.46 & 3.59 & 14.91 & 15.67 \\
\hline NPP & 70.53 & 40.60 & $53.95-88.95$ & $31.80-57.10$ & 13.15 & 12.49 & 14.62 & 14.45 & 81.00 & 75.00 & 9.90 & 15.70 & 24.38 & 22.26 \\
\hline DMT & 90.81 & 88.70 & $87.10-95.30$ & $86.10-91.60$ & 0.345 & 1.53 & 2.17 & 8.63 & 25.00 & 34.00 & 0.10 & 1.65 & 0.11 & 1.82 \\
\hline YPP & 18.21 & 14.43 & $13.35-29.60$ & $9.78-27.30$ & 22.69 & 19.40 & 24.03 & 20.82 & 89.00 & 87.00 & 6.37 & 6.78 & 44.16 & 37.26 \\
\hline PVP & 81.69 & 71.97 & $63.10-96.30$ & $54.30-84.30$ & 7.66 & 10.48 & 9.05 & 11.85 & 72.00 & 78.00 & 9.61 & 15.62 & 13.35 & 19.12 \\
\hline HSW & 27.24 & 22.67 & $18.10-33.90$ & $18.80-25.50$ & 7.72 & 14.49 & 9.76 & 15.42 & 63.00 & 88.00 & 2.65 & 7.64 & 12.37 & 28.07 \\
\hline PML50 & 56.27 & 51.43 & $38.80-71.30$ & $38.70-75.40$ & 13.82 & 13.14 & 14.60 & 14.16 & 89.00 & 86.00 & 13.86 & 14.13 & 26.95 & 25.11 \\
\hline TCC50 & 1.67 & 1.05 & $1.10-2.25$ & $0.56-1.32$ & 18.92 & 15.01 & 19.96 & 17.21 & 87.00 & 76.00 & 0.38 & 0.45 & 36.84 & 26.98 \\
\hline Wilt \% & 10.64 & 9.35 & $6.45-78.60$ & $7.09-81.70$ & 27.98 & 107.92 & 29.37 & 118.90 & 90.00 & 91.00 & 5.42 & 6.50 & 54.94 & 69.50 \\
\hline
\end{tabular}

DFF: Days to first flowering, D50F: Days to 50 per cent flowering, DFP: Days to first podding, D50P: Days to 50 per cent podding, NPB: Number of primary branches, PHT: Plant height $(\mathrm{cm})$, FPH: First pod height $(\mathrm{cm})$, NPP: Number of pods per plant, DMT: Days to maturity, YPP: Yield per plant (g), HSW: Hundred seed weight (g), PVP: Pollen viability (\%), PML50: Per cent membrane leakage at 50 days, TCC50 - Total chlorophyll content at 50days, Wilt (\%): Wilting per cent 
Table.3 Genotypic correlations among eleven quantitative traits of $F_{3}$ (rabi 2017) and $F_{4}$ (summer 2018) progenies

\begin{tabular}{|c|c|c|c|c|c|c|c|c|c|c|c|}
\hline Traits & D50F & D50P & NPB & PHT & FPH & NPP & DMT & HSW & PML50 & TCC50 & YPP \\
\hline NPB & $0.521 * *$ & $0.759 * *$ & 1.000 & $0.463 * *$ & 0.172 & $0.470 * *$ & 0.225 & $0.358 *$ & $-0.589 * *$ & -0.151 & 0.372 \\
\hline FPH & $0.638 * *$ & $0.834 * *$ & $0.680 * *$ & $0.671 * *$ & 1.000 & $0.493 * *$ & $0.662 * *$ & 0.136 & $-0.318 *$ & $-0.381 *$ & 0.303 \\
\hline NPP & $0.487 * *$ & $0.641 * *$ & $0.647 * *$ & $0.701 * *$ & $0.719 * *$ & 1.000 & 0.221 & $0.480 * *$ & $-0.295^{*}$ & -0.177 & 0.344 \\
\hline DMT & $0.789 * *$ & $0.918 * *$ & $0.849 * *$ & $0.926 * *$ & $0.784 * *$ & $0.523 * *$ & 1.000 & $0.666 * *$ & -0.250 & $0.339 *$ & 0.026 \\
\hline PML50 & $0.532 * *$ & $0.621 * *$ & $0.347 * *$ & $0.497 * *$ & $0.729 * *$ & $0.522 * *$ & $0.486^{* *}$ & -0.007 & 1.000 & $0.342 *$ & -0.571 \\
\hline TCC50 & $0.266^{*}$ & $0.280 *$ & $0.611 * *$ & $0.284 *$ & -0.079 & $0.253^{*}$ & 0.197 & -0.155 & -0.051 & 1.000 & -0.103 \\
\hline YPP & 0.535 & 0.516 & 0.477 & 0.475 & 0.582 & 0.516 & 0.572 & 0.388 & 0.604 & 0.327 & - \\
\hline
\end{tabular}

Values below the diagonal indicate genotypic correlations of timely sown environment, Values above diagonal indicate genotypic correlations for late sown environment

$*, * *$ and $* * *$ indicates significance at $5 \%, 1 \%$ and $0.1 \%$ respectively.

D50F: Days to 50 per cent flowering, D50P: Days to 50 per cent podding, NPB: Number of primary branches, PHT: Plant height (cm), FPH: First pod height $(\mathrm{cm})$, NPP: Number of pods per plant, DMT: Days to maturity, YPP: Yield per plant (g), HSW: Hundred seed weight (g), PML50: Per cent membrane leakage at 50 days, TCC50 - Total chlorophyll content at 50days 
It is evident from the results (Table 2) that the there is a lack of variability in the material studied for the characters viz., number of branches per plant and days to physiological maturity, since these traits had moderate GCV to low GCV in both the seasons. Generally lower variability has been reported for these traits in chickpea. Therefore in order to improve these traits it is necessary to create variability by hybridization or mutagenesis (Aher et al., 2014 and Desai et al., 2017)

The higher values of GCV and PCV indicated ample variability under both the situations. Heritability helps to know the extent of genetic expression in a given environment. Higher heritability for days to first and fifty per cent podding, days to maturity, pollen viability and hundred seed weight was noticed under late sown environments. It could be because these traits expressed more distinctly in heat stress environments (Paul et al., 2018). Higher estimates of GCV (\%), heritability and genetic advance as per of mean were noticed for plant height $(\mathrm{cm})$, first pod height $(\mathrm{cm})$, number of pods per plant, yield per plant (g/plant) and hundred seed weight ( $\mathrm{g}$ ). Occurrence of high estimates of heritability coupled with genetic advance as per cent of mean for these traits suggest that these traits can be considered as favourable attributes for improvement through selection as additive gene action may be pre-dominant in expression of these traits (Anand Kumar et al., 2017). Further higher GCV and PCV under stress environments and moderate GCV and PCV under non-stress environments indicate large effects of heat stress on the progenies for creating variation in them (Paul et al., 2018).

Correlation analysis provides a good measure of the linear association between character(s) and helps to identify the most important character(s) to be considered to be effective in selection for yield increment. The knowledge of genetic association among seed yield and its component helps in improving the efficiency of selection for yield components for maximum genetic gain. Under timely sown condition, the phenological and yield attributes were positively and significantly associated with yield per plant (Table 3). However, hundred seed weight registered negative and significant correlations with days to fifty per cent podding (-0.553), number of branches per plant $(-0.615)$, plant height (-0.552), first pod height $(-0.621)$ and number of pods per plant (-0.546). Under late sown conditions, among the yield attributes number of pods per plant was positively and significantly associated with number of branches per plant (0.470), plant height (0.509) and first pod height (0.493). The trait hundred seed weight was positively and significantly associated with number of pods per plant (0.480) and days to maturity (0.666). Increase in seed size under heat stress leads to reduction in number of seeds as well as seed yield. This signifies that early maturing genotypes with better canopy spread are capable of high yield under late sown environment. Per cent membrane leakage at 50 days showed significant negative correlation with yield per plant under late sown condition. This is because adverse effect of temperature stress on the membrane leads to disruption of cellular activity. Injury to membranes from a sudden heat stress event results from either denaturation of the membrane proteins or from melting of membrane lipids, which leads to membrane rupture and loss of cellular contents (Pouresmaela et al., 2013).

Early maturing varieties can escape the adverse effects of heat stress on yield. Paul et $a l$. , (2018) opined that higher yield under heat stress could be achieved through higher number of filled pods per plant and seeds rather than seed mass. Plant height, number of pods per plant, hundred seed weight and per 
cent membrane leakage at 50 days were identified as important traits under late sown environment.

\section{References}

Aher B M, Desai A, Pithia M S and Kalyanrao. 2014. Genetic variability of yield and its contributing characters in Kabuli chickpea (Cicer arietinum L.). Trends Biosci. 7 (23): 4025-4032.

Anand Kumar, Agarwal, T, Sanjay Kumar, Anil Kumar, Kumar, R. R., Manoj Kumar, Chandhan Kishore and Singh P. K., 2017. Identification and evaluation of heat tolerant chickpea genotypes for enhancing its productivity in rice fallow area of Bihar and mitigating impacts of climate change. Journal of Pharmacognosy and Phytochemistry. SP1: 1105-1113.

Burton, G. N. and Devane, E. M., 1953. Estimating heritability in fall fescue (Festuca arundiacea L.) from replicated clonal material. Agron. J., 45(2): 478481.

Desai, P. B., Patil, B. A., Vijayakumar, A. G. and Basavarajappa, M. P., 2017. A comparative analysis of genetic variability and correlation in chickpea under normal and late sown conditions. Green Farming, 8(2): 266-270.

Devasirvatham V, Gaur P M, Mallikarjuna N, Tokachichu R N, Trethowan R M and Tan D K Y. 2012. Effect of high temperature on the reproductive development of chickpea genotypes under controlled environments. Funct. Plant Biol. 39: 1009-1018

Devasirvatham, V., Gaur, P. M., Mallikarjuna, N., Raju, T. N., Trethowan, R. M., and Tan, D. K. Y., 2013. Reproductive biology of chickpea response to heat stress in the field is associated with the performance in controlled environments. Field Crops
Research, 142, 9-19

Devasirvatham, V., Gaur, P. M., Raju, T. N., Trethowan, R. M., and Tan, D. K. Y., 2015. Field response of chickpea (Cicer arietinum L.) to high temperature. Field Crops Research, 172, 59-71.

Dixit G. P., A. K. Srivastava and N. P. Singh, 2019. Marching towards selfsufficiency in chickpea. Current Science. 116 (2): 239 - 242.

Gaur P. M, Samineni S, Thudi M, Shailesh T, Shoban B. S, Jayalakshmi. V, Mannur, D. M, Vijayakumar A. G, Ganga Rao N. V. P. R, Ojiewo. C, Asnake F, Kimurto P, Robert O. K, Girma N, Chaturvedi, S. K, Varshney R. K and Dixit G. P, 2018. Integrated breeding approaches for improving drought and heat adaptation in chickpea (Cicer arietinum L). Plant Breeding, 1-12.

Hanson, G. H., Robinson, H. F. and Comstock, R. E., 1956. Biometrical studies of yield in segregating population of Korean Lespodzoa. Agron. J., 48(2): 267-282.

Johnson, H. W., Robinson, H. F. and Comstock, R. E., 1955. Estimate of genetic and environmental variability in soybean. Agron. J., 47(6): 314-318.

Paul, P. J., Samineni, S., Sajja, S. B., Rathore, A., Das, R. R., Chaturvedi, S. K, Lavanya G. R, Varshney R. K and Gaur, P. M, 2018. Capturing genetic variability and selection of traits for heat tolerance in a chickpea recombinant inbred lines (RIL) population under field conditions. Euphytica, 214: 27

Pouresmaela M., Ramazan Ali KhavariNejada, C., Javad M., Farzaneh N. and Foad M., 2013. Efficiency of screening criteria for drought tolerance in chickpea, Archives Agron. Soil Sci., 59(12): 1675-1693.

Upadhaya, H. D., Dronavalli, N., Gowda, C. L. L. and Singh, S., 2011. Identification 
and evaluation of chickpea germplasm for tolerance to heat stress. Crop Sci., 51: 2079-2094.

Weber and Moorthy B R. 1950. Heritable and non-heritable relationship and variability of oil content and agronomic characteristics in the $\mathrm{F}_{2}$ generation of soybean crosses. Agron. J. 44: 202-209.

\section{How to cite this article:}

Vijayakumar, A.G., H.L. Nadaf, V.B. Nargund and Patil, B.C. 2019. Genetic Variability and Correlation Studies in Chickpea under Timely and Late Sown Environments. Int.J.Curr.Microbiol.App.Sci. 8(07): 2590-2597. doi: https://doi.org/10.20546/ijcmas.2019.807.319 